This document is confidential and is proprietary to the American Chemical Society and its authors. Do not copy or disclose without written permission. If you have received this item in error, notify the sender and delete all copies.

\title{
Investigation of the Relationship between the Structure and Conductivity of the Novel Oxide Ionic Conductor Ba3MoNb08.5
}

\begin{tabular}{|r|l|}
\hline Journal: & Chemistry of Materials \\
\hline Manuscript ID & cm-2017-012986.R1 \\
\hline Manuscript Type: & Article \\
\hline Date Submitted by the Author: & 19-Apr-2017 \\
\hline & $\begin{array}{l}\text { Fop, Sacha; University of Aberdeen, The Chemistry Department } \\
\text { Wildman, Eve; University of Aberdeen, The Chemistry Department } \\
\text { Irvine, John; University of St Andrews, Chemistry } \\
\text { Connor, Paul; University of St Andrews, Chemistry } \\
\text { Skakle, Janet; University of Aberdeen, Chemistry } \\
\text { Ritter, Clemens; Avenue des Martyrs 156x, Institute Laue-Langevin } \\
\text { McLaughlin, Abbie; University of Aberdeen, Chemistry }\end{array}$ \\
\hline \hline
\end{tabular}

SCHOLARONE

Manuscripts 


\section{INTRODUCTION}

Solid oxide electrolytes are the basis of two important energy technologies, Solid Oxide Fuel Cells (SOFCs) and Solid Oxide Electrolyser Cells (SOECs). SOFCs offer an efficient alternative to combustion technology for electricity production. The advantages of the high operating temperature for SOFCs include the possibility of running directly on practical hydrocarbon fuels without the need for complex and expensive external fuel reformer and purification systems. The high quality exhaust heat released during operation can be used as a valuable energy source, either to drive a gas turbine when pressurized or for combined heat and power (CHP) applications, so further increasing system efficiency.

To date, oxide ion conductivity has been reported in a number of structural families including fluorite-like systems ", silicon and germanium apatites ${ }^{2}, \mathrm{La}_{2} \mathrm{Mo}_{2} \mathrm{O}_{9}$ (LAMOX) materials ${ }^{3}, \mathrm{Bi}_{4} \mathrm{~V}_{2} \mathrm{O}_{11}$ derivatives (BIMEVOX) ${ }^{4}$ and complex oxides with $\mathrm{GaO}_{4}$ tetrahedral moieties ${ }^{5}$. To simplify certain materials issues, such as sealing and to enable the use of cheaper steel interconnects, it is desirable to lower the SOFCs' operating temperature from 800 ${ }^{\circ} \mathrm{C}$, to an intermediate range of $400{ }^{\circ} \mathrm{C}-600{ }^{\circ} \mathrm{C}^{6}$. So far, materials that exhibit high conductivity at low temperature, such as aliovalent doped ceria or isovalent cation stabilised bismuth oxide, are less stable under the reducing fuel environment. The oxide ion conductivity of a material is strongly dependent on the crystal structure, hence in order to reach the objective of an intermediate temperature fuel cell it is important to discover new structural families of oxide ion conducting materials.

The perovskite structural family offers great potential for the discovery of new oxide ion conductors due to its structural adaptability. Several perovskite materials with high oxide ion conductivity have been reported including strontium and magnesium-doped lanthanum gallates $\left(\right.$ LSGM) ${ }^{7}$ and more recently the well-known ferroelectric material $\mathrm{Na}_{0.5} \mathrm{Bi}_{0.5} \mathrm{TiO}_{3}{ }^{8}$ and the perovskite derivative $\mathrm{NdBaInO}_{4}{ }^{9}$. We have recently identified oxide ion conductivity in $\mathrm{Ba}_{3} \mathrm{MoNbO}_{8.5}{ }^{10}$ which exhibits a bulk conductivity of $2.2 \times 10^{-3} \mathrm{~S} \mathrm{~cm}^{-1}$ at $600{ }^{\circ} \mathrm{C}$. $\mathrm{Ba}_{3} \mathrm{MoNbO}_{8.5}$ crystallises in a hybrid of the ${ }_{9} \mathrm{R}$ hexagonal perovskite and palmierite structures, which is a novel and so far unique crystal structure. Units of $(\mathrm{Mo} / \mathrm{Nb}) \mathrm{O}_{4}$ and $(\mathrm{Mo} / \mathrm{Nb}) \mathrm{O}_{6}$ coexist within the structure, forming a disordered arrangement of $\mathrm{Mo} / \mathrm{Nb}$ tetrahedra and octahedra. $\mathrm{Ba}_{3} \mathrm{MoNbO}_{8.5}$ exhibits oxygen transport numbers of 0.99 in air $/ \mathrm{O}_{2}$ and 0.92 in air $/ 5 \% \mathrm{H}_{2}$ in $\mathrm{Ar}$ at $600{ }^{\circ} \mathrm{C}$, suggesting that $\mathrm{Ba}_{3} \mathrm{MoNbO}_{8.5}$ is an oxide ion conductor with negligible electronic conductivity in air $/ \mathrm{O}_{2}$ and that a small amount of electronic conduction is observed in air $/ 5 \% \mathrm{H}_{2}$ in Ar. The phase is also surprisingly stable in $5 \% \mathrm{H}_{2} / \mathrm{N}_{2}{ }^{10}$. $\mathrm{Ba}_{3} \mathrm{MoNbO}_{8.5}$ is the first hexagonal perovskite to display such promising transport numbers / oxide ion transport at low temperature. All other hexagonal systems previously reported exhibit mixed oxide ion and electronic and/or proton conductivi- 
ty with low conductivities and low transport numbers ${ }^{11,12}$. In order to further investigate the correlation between the structural and the transport properties in $\mathrm{Ba}_{3} \mathrm{MoNbO}_{8.5}$ we have performed a variable temperature neutron diffraction study between 25 to $600{ }^{\circ} \mathrm{C}$. A structural rearrangement occurs above $300{ }^{\circ} \mathrm{C}$ so that the ratio of $(\mathrm{Mo} / \mathrm{Nb}) \mathrm{O}_{4}$ tetrahedra to $(\mathrm{Mo} / \mathrm{Nb}) \mathrm{O}_{6}$ octahedra increases upon heating between $300{ }^{\circ} \mathrm{C}$ and $600{ }^{\circ} \mathrm{C}$. The results demonstrate that there is a strong correlation between the number of tetrahedra within the average structure and the observed ionic conductivity.

\section{EXPERIMENTAL}

Stoichiometric amounts of $\mathrm{BaCO}_{3}$ (99.999\%, Aldrich), $\mathrm{MoO}_{3}$ (99.5+\%, Aldrich) and $\mathrm{Nb}_{2} \mathrm{O}_{5}$ (99.99\%, Aldrich) were ground, pressed into $13 \mathrm{~mm}$ pellets and calcined in an alumina crucible at $900{ }^{\circ} \mathrm{C}$ for 10 hours. The pellets were subsequently reground, pelleted and heated at 1100 ${ }^{\circ} \mathrm{C}$ for 48 hours and then cooled to room temperature at 5 ${ }^{\circ} \mathrm{C} / \mathrm{min}$. The latter heating step was repeated until phase pure products were obtained.

Variable temperature neutron diffraction patterns in the temperature range 25 to $600{ }^{\circ} \mathrm{C}$ were recorded on the high-resolution powder diffractometer $\mathrm{D}_{2} \mathrm{~B}$ at the Institut Laue-Langevin (ILL) in Grenoble, France. A sample of 5 grams of $\mathrm{Ba}_{3} \mathrm{MoNbO}_{8.5}$ was inserted in an open quartz tube and heated up to the desired temperatures. Data were collected at $\lambda=1.59432 \AA$ with a total collection time of 2.5 hours for each temperature step.

For the impedance spectroscopy measurements, a pellet of $\sim 10 \mathrm{~mm}$ diameter and $\sim 1.5 \mathrm{~mm}$ thickness was prepared from a powder sample of $\mathrm{Ba}_{3} \mathrm{MoNbO}_{8.5}$ and sintered at $1100{ }^{\circ} \mathrm{C}$ for 48 hours (to achieve $>95 \%$ of the theoretical density). Pt electrodes were painted on both sides of the pellet using a Pt-paste (Metalor 6o82). Impedance spectra were recorded with a Solartron 1260 impedance analyser in the frequency range $0.1 \mathrm{~Hz}-1 \mathrm{MHz}$ with an applied alternating voltage of $0.1 \mathrm{~V}$. Data were recorded upon cooling from $600{ }^{\circ} \mathrm{C}$ to $300{ }^{\circ} \mathrm{C}$ in a sealed tube furnace under the flow of dry air, measuring every $15{ }^{\circ} \mathrm{C}$ and allowing 2 hours of equilibration at each temperature step. The obtained data were corrected by the geometrical factor of the sample and treated with the ZView software (Scribner Associates, Inc.). The data were fitted using the model described previously ${ }^{10}$.

\section{RESULTS AND DISCUSSION}

Neutron diffraction data at all temperatures were fitted by the Rietveld method using the GSAS/EXPGUI program 13, ${ }^{14}$. Modelling of the background was performed by the shifted Chebyschev polynomial function and the peak shapes were fitted using a Pseudo-Voigt function. The hybrid $9 \mathrm{R}$ polytype - palmierite model previously reported ${ }^{10}$ (Figure 1) was used as a starting model for the variable temperature refinements. This model is formed by a disordered arrangement of Mo and $\mathrm{Nb}$ cations in mixed tetrahedral - octahedral coordination, which is created by the occupation of both the $9 e$ ( $9 \mathrm{R}$ polytype) and $6 c$ (palmierite) oxygen positions. Oxygen atoms are present at three different Wyckoff sites: $\mathrm{O}(1)$ in $18 h, \mathrm{O}(2)$ in $9 e$ and
$\mathrm{O}(3)$ in $36 i$; the latter position is employed instead of $6 c$ to take into account the dynamic disorder evidenced by the large $U_{11}, U_{22}$ and $U_{12}$ values for $\mathrm{O}(3)$ found in the previous structural refinement ${ }^{10}$. Mo/Nb cations $(\mathrm{M})$ are in $6 c$ and $3 b$, while the Ba atoms occupy the $6 c$ and $3 a$ sites.

An excellent fit to the neutron data was obtained with the hybrid model described above for all temperatures (the refined data recorded at $25{ }^{\circ} \mathrm{C}$ and $600{ }^{\circ} \mathrm{C}$ are displayed in Figure 2, while the Rietveld fits to the data collected at the remaining temperatures are presented in the Supporting Information).

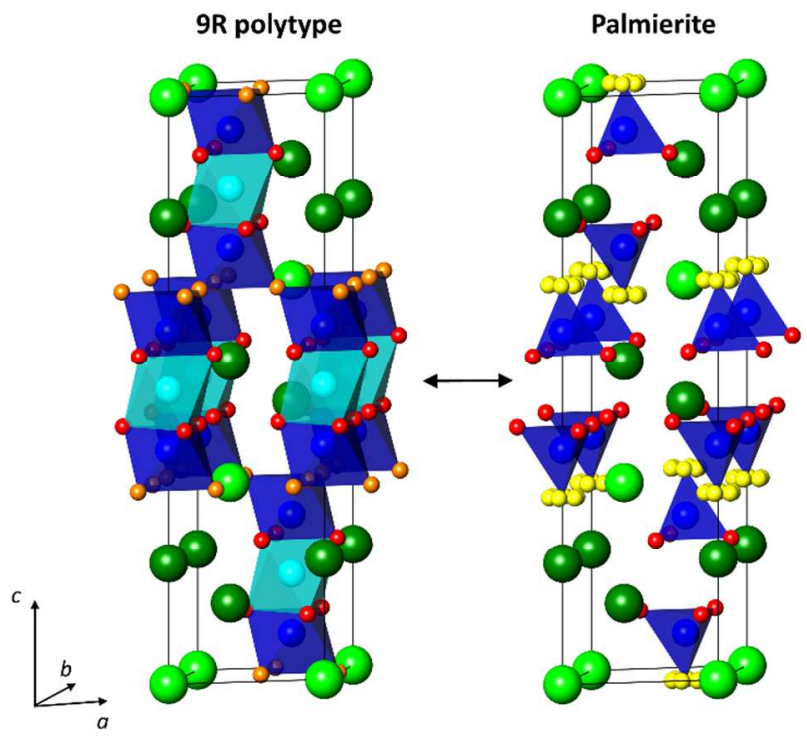

Figure 1. Crystal structure of $\mathrm{Ba}_{3} \mathrm{MoNbO}_{8.5}$. The hybrid structural model formed by the superimposition of the 9R-polytype and the palmierite sub-units representing the average structure of the system. Colours indicate: light green $\mathrm{Ba}(1)$, dark green $\mathrm{Ba}(2)$, blue $\mathrm{M}(1)$, cyan $M(2)$, red $O(1)$, orange $O(2)$ and yellow $O(3)$.

There is no evidence of peak splitting or superstructure peaks and the $R \overline{3} m$ H symmetry space group is observed over the whole temperature range. The refined atomic positions and agreement indices are displayed in Table S1. The atomic displacement parameters, $U_{\mathrm{ij}}$, were refined anisotropically for all atoms except $\mathrm{O}(3)$, for which an $U_{\text {iso }}$ parameter was used as previously reported ${ }^{10}$. Attempts to independently refine the $\mathrm{M}(1)$ and $\mathrm{M}(2) U_{\mathrm{ij}}$ parameters generated unrealistic $U_{33}$ values; therefore the $U_{\mathrm{ij}}$ parameters of the $\mathrm{M}$ atoms on the $6 c$ and $3 b$ sites were constrained to be the same. The displacement parameters for all atoms are reported in Table S1. The atomic $U_{\mathrm{ij}}$ anisotropic values generally increase with the temperature as expected. Overall, the obtained thermal displacement values are within the range expected for this type of material, with similar values being found for $\alpha$ - and $\beta$ $\mathrm{La}_{2} \mathrm{Mo}_{2} \mathrm{O}_{9}{ }^{15}, \gamma-\mathrm{Bi}_{4} \mathrm{~V}_{2} \mathrm{O}_{11}{ }^{16}, \mathrm{La}_{1.54} \mathrm{Sr}_{\mathrm{o} .46} \mathrm{Ga}_{3} \mathrm{O}_{7.27}{ }^{5}$, and LSGM materials ${ }^{17}$. The large $U_{33}$ values indicate that the M cations exhibit motion mainly parallel to the $c$-axis ( Figure S2). $\mathrm{Ba}(1)$ presents $U_{11}=U_{22}>U_{33}$, indicating preferential thermal motion on the $a b$ plane. On the contrary, the $\mathrm{Ba}(2)$ atom shows larger $U_{33}$ values, evidencing aniso- 
tropic motion along the $\mathrm{c}$-axis. $\mathrm{Ba}(1)$ is encircled by a belt of $\mathrm{O}(2)$ and $\left.\mathrm{O}_{3}\right)$ sites, while $\mathrm{Ba}(2)$ and $\mathrm{M}(1)$ are directly above (or below) the $\mathrm{O}(2)$ and $\mathrm{O}(3)$ positions. The distribution of occupied/unoccupied $\mathrm{O}(2)$ and $\mathrm{O}(3)$ sites creates different coordination environments for the metal cations, thus inducing motion on the $a b$ plane $(\mathrm{Ba}(1))$ or along the $c$-axis $(\mathrm{Ba}(2)$ and $\mathrm{M}(1))$. The $\mathrm{O}(1)$ thermal ellipsoids are oriented perpendicularly to the $\mathrm{M}-\mathrm{O}$ bonds. The $\mathrm{O}(2)$ ellipsoids are nearly spherical in the whole temperature range and $\mathrm{O}_{3}$ ) exhibits large $U_{\text {iso }}$ values as previously reported ${ }^{10}$.

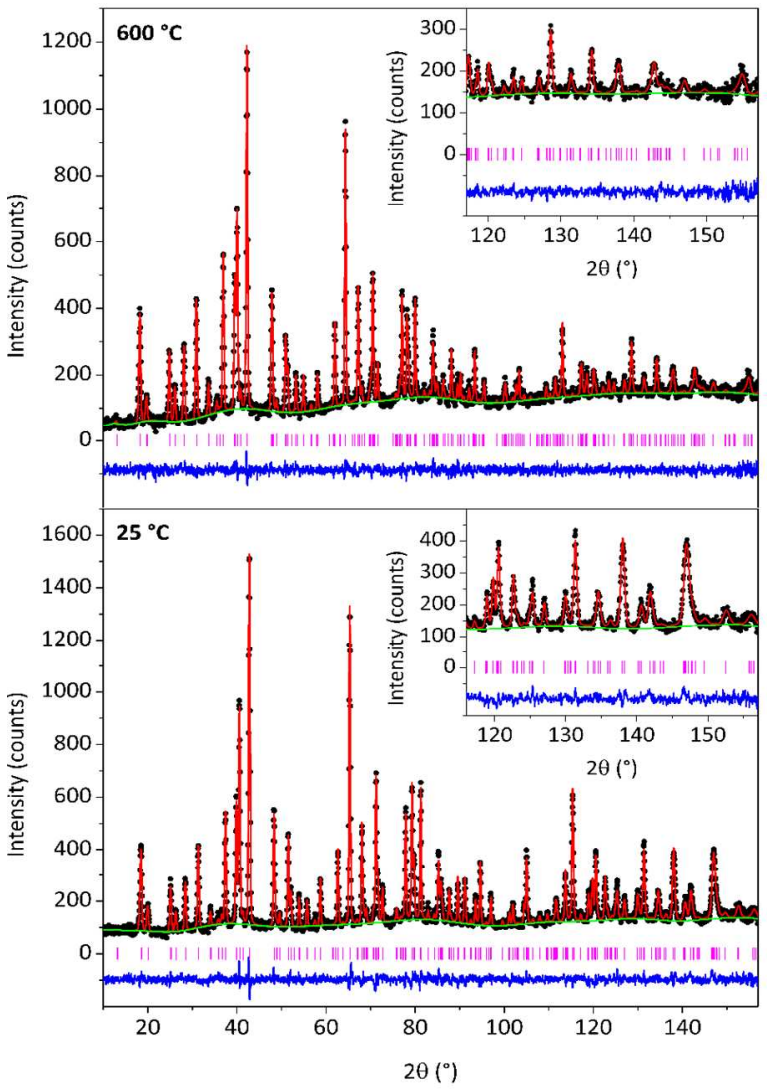

Figure 2. Rietveld refinement fit to the variable temperature neutron diffraction data of $\mathrm{Ba}_{3} \mathrm{MoNbO}_{8.5}$. Rietveld refinement fits of neutron diffraction data collected at $25^{\circ} \mathrm{C}$ and $600{ }^{\circ} \mathrm{C}$ are shown. Black dots indicate the observed data, the red line the Rietveld fit, the blue line the difference between the observed and the calculated patterns, the green line the background function and the pink bars are the reflection positions.

The temperature dependency of the $a$ and $c$ cell parameters are shown in Figure 3 and non-monotonic behaviour is observed. A clear change in slope of both $a$ and $c$ is observed above $300{ }^{\circ} \mathrm{C}$ suggesting a possible structural modification. The fractional occupancies of the atoms in the structural model obtained previously ${ }^{10}$ were used as starting values for the refinement of the variable temperature neutron diffraction data. The $\mathrm{Ba}$ and $\mathrm{O}(1)$ fractional occupancies refined to within $\pm 1 \%$ of full occupancy and were fixed at 1.o. The occupancies of the other atoms were refined from their initial values. The refined fractional occupancies are presented in Table S1. Figure 4 shows the temperature dependency of the fractional occupancies of $\mathrm{M}(1), \mathrm{M}(2), \mathrm{O}(2)$ and $\mathrm{O}(3)$.

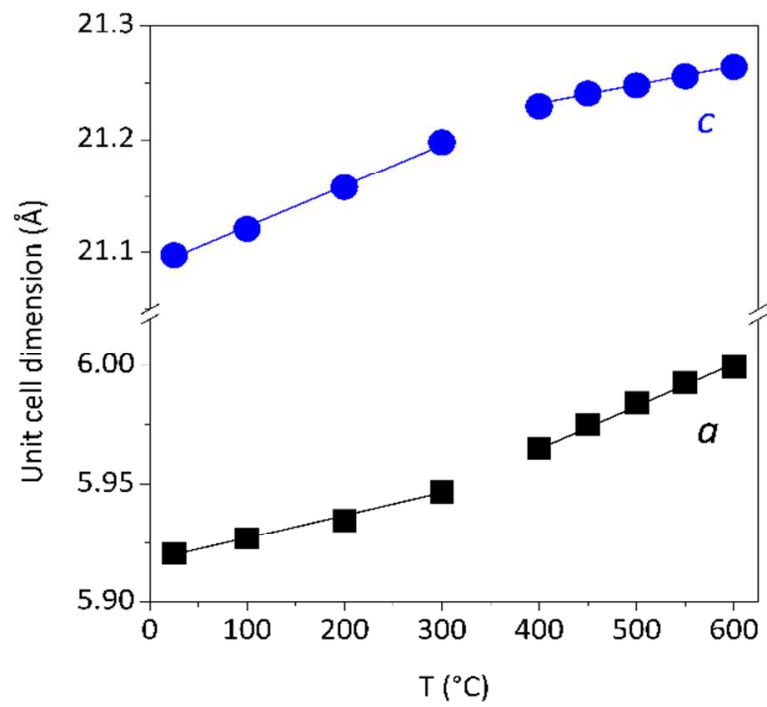

Figure 3. Unit cell dimensions of $\mathrm{Ba}_{3} \mathrm{MoNbO}_{8.5}$. Thermal dependency of the $a$ - and $c$-axis of the unit cell of $\mathrm{Ba}_{3} \mathrm{MoNbO}_{8.5}$. The linear fits evidence the change in slope above $300{ }^{\circ} \mathrm{C}$.

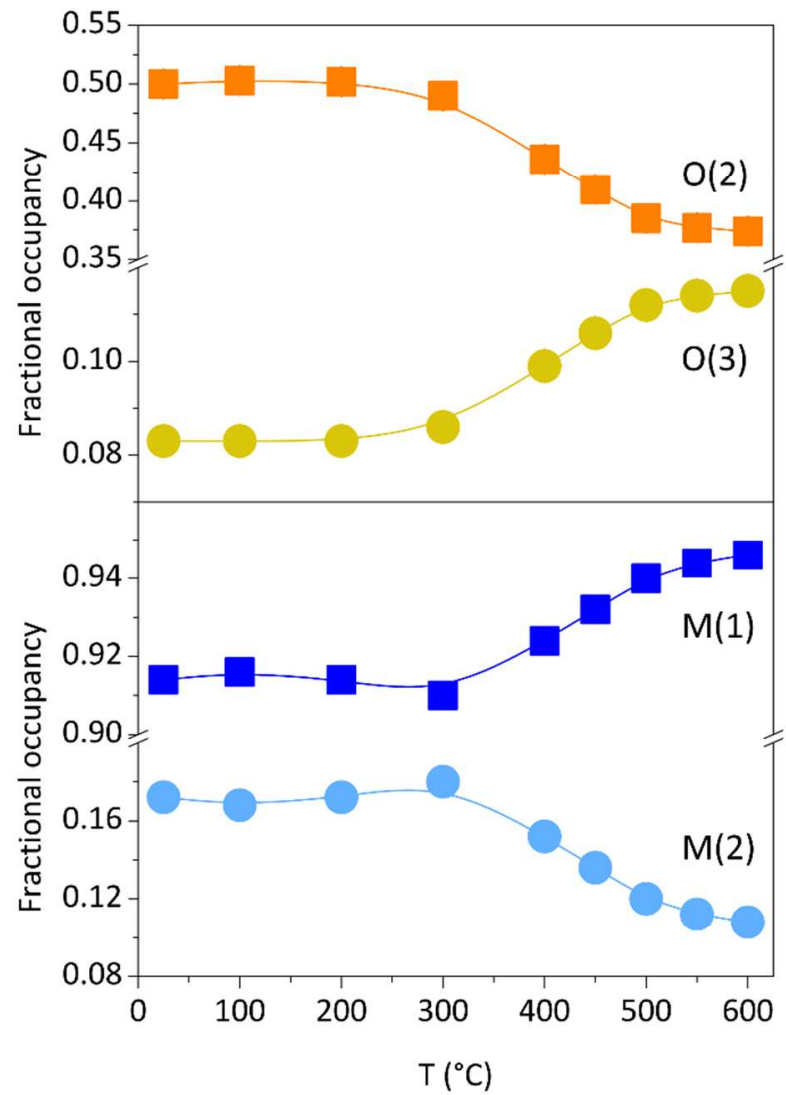

Figure 4. Variation of fractional occupancies with the temperature. Temperature dependency of the fractional occupancies of $\mathrm{M}(1)$ and $\mathrm{M}(2)$ and $\mathrm{O}(2)$ and $\mathrm{O}(3)$. Connecting lines are guides for the eye only. 
There is little change in the fractional occupancies between $25^{\circ} \mathrm{C}-300{ }^{\circ} \mathrm{C}$. Above this temperature a sudden increase in the $\mathrm{M}(1)$ fractional occupancy, with a concomitant decrease in the $\mathrm{M}(2)$ fractional occupancy, is evidenced. The same behaviour is observed for the $\mathrm{O}(2)$ and $\mathrm{O}(3)$ fractional occupancies, which respectively decrease and increase above $300{ }^{\circ} \mathrm{C}$. Above $500{ }^{\circ} \mathrm{C}$ there is little variation in the fractional occupancies of $\mathrm{M}(1), \mathrm{M}(2), \mathrm{O}(2)$ and $\mathrm{O}(3)$. An overall oxygen stoichiometry of 8.5 was obtained at all temperatures.

$\mathrm{Ba}(1), \mathrm{Ba}(2)$ and $\mathrm{O}(1)$ form the rigid part of the $\mathrm{Ba}_{3} \mathrm{MoNbO}_{8.5}$ structure, while $\mathrm{M}(1), \mathrm{M}(2), \mathrm{O}(2)$ and $\mathrm{O}(3)$ are responsible for the variable tetrahedral/octahedral coordination. Therefore, changes in the occupancies of the latter atoms indicate that the structure is able to adjust the ratio of tetrahedra to octahedra and, consequently, oxygen/vacancy distributions as the temperature increases. The results demonstrate that the number of $(\mathrm{Mo} / \mathrm{Nb}) \mathrm{O}_{4}$ tetrahedra increases upon heating above 300 ${ }^{\circ} \mathrm{C}$.

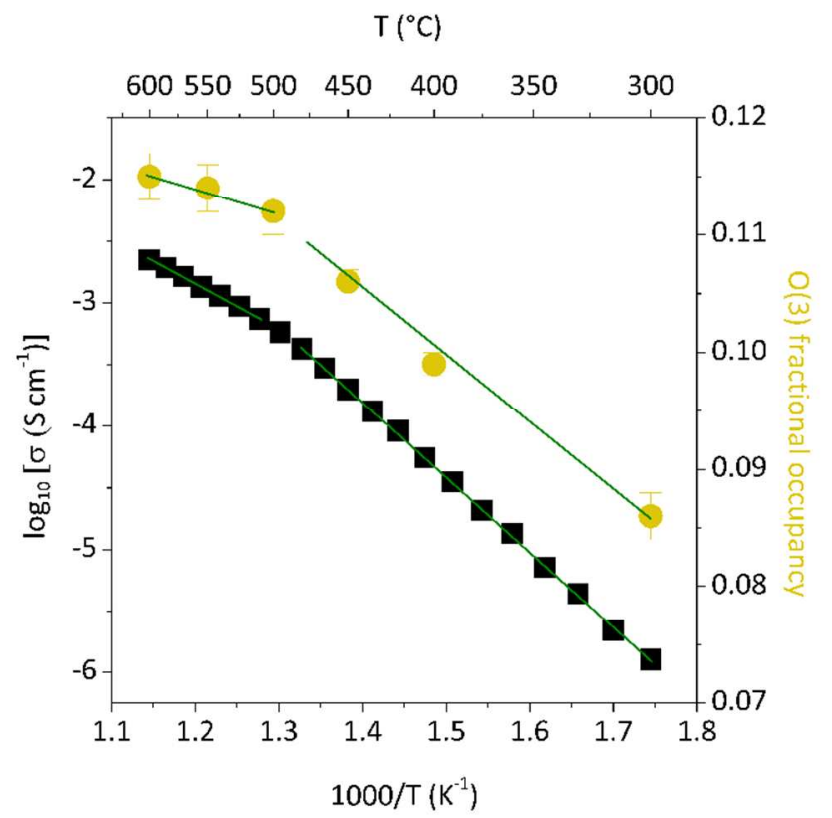

Figure 5. A comparison of the thermal variation of the fractional occupancy of $\mathrm{O}(3)$ and the Arrhenius plot of the bulk conductivity of $\mathrm{Ba}_{3} \mathrm{MoNbO}_{8.5}$.

The variation of the fractional occupancy of $\mathrm{O}_{3}$ ) and the Arrhenius plot of the bulk conductivity of $\mathrm{Ba}_{3} \mathrm{MoNbO}_{8.5}$ is presented in Figure 5. The bulk conductivity is $2.2 \times 10^{-3} \mathrm{~S} \mathrm{~cm}^{-1}$ at $600{ }^{\circ} \mathrm{C}$ with an activation energy of 1.211 (6) $\mathrm{eV}$ for temperatures between $300-500{ }^{\circ} \mathrm{C}$. There is a clear correlation between the change in the crystal lattice and the electrical properties at temperatures between $300{ }^{\circ} \mathrm{C}$ and $600{ }^{\circ} \mathrm{C}$. The rearrangement of $\mathrm{M}(1), \mathrm{M}(2), \mathrm{O}(2)$ and $\mathrm{O}(3)$ within the crystal structure results in an increase of the ratio of $\mathrm{M}(1) \mathrm{O}_{4}$ tetrahedra to $\mathrm{M}(1) \mathrm{O}_{6}$ octahedra with concomitant changes in the bond lengths and angles. At $300{ }^{\circ} \mathrm{C}$ there are $\sim 49.9 \%$ tetrahedra within the average structure which increases to
$63.5 \%$ at $500{ }^{\circ} \mathrm{C}$. Above $500{ }^{\circ} \mathrm{C}$ the rate of increase in the number of tetrahedra within the crystal structure of $\mathrm{Ba}_{3} \mathrm{MoNbO}_{8.5}$ decreases so that at $600{ }^{\circ} \mathrm{C}$ there are $64.8 \%$ tetrahedra. At the same time a change in slope is evidenced in the Arrhenius plot. The results clearly demonstrate that the magnitude of ionic conductivity observed in $\mathrm{Ba}_{3} \mathrm{MoNbO}_{8.5}$ is strongly related to the number of $\mathrm{Mo} / \mathrm{NbO}_{4}$ tetrahedra within the average crystal structure.

Increasing the number of $(\mathrm{Mo} / \mathrm{Nb}) \mathrm{O}_{4}$ tetrahedra most likely offers more low energy transition paths for transport of the $\mathrm{O}^{2-}$ ions, further enhancing the conductivity. The preference for a tetrahedral environment gives a large number of possible oxygen positions which are important for collective mechanisms involving strongly correlated motions of sets of tetrahedra as previously observed for the brownmillerite $\mathrm{Ba}_{2} \mathrm{In}_{2} \mathrm{O}_{5}{ }^{18}$.

The self-rearrangement of the $\mathrm{Mo} / \mathrm{Nb}$ and oxygen occupancies is striking evidence of the ability of the metal lattice to support variable coordination environments. It has been demonstrated that the presence of flexible $d$ metal cations is essential for the ionic transport of various oxide ion conductors. The high oxygen conduction of $\beta$ $\mathrm{La}_{2} \mathrm{Mo}_{2} \mathrm{O}_{9}$ is thought to be facilitated by the capacity of the molybdenum atom to assume co-ordinations between 4 and $6^{3,19}$. In the BIMEVOX materials the oxygen motion proceeds through the decomposition and reformation of the $\mathrm{V}-\mathrm{O}$ units on the perovskite layers. An oxygen atom is transferred from a $\mathrm{VO}_{6}$ octahedron to a vacancy contained in a nearby $\mathrm{V}^{\prime} \mathrm{O}_{4}$ tetrahedron, forming a shortliving $\mathrm{VO}_{5} \mathrm{~V}^{\prime} \mathrm{O}_{5}$ complex. The complex then separates into a $\mathrm{VO}_{4}$ tetrahedron and a $\mathrm{V}^{\prime} \mathrm{O}_{6}$ octahedron, completing the oxygen migration ${ }^{20}$. In the same way, $\mathrm{Ba}_{3} \mathrm{MoNbO}_{8.5}$ possesses a flexible lattice in which the $\mathrm{M}$ atoms are readily able to change coordination, creating a potential avenue for conduction as it is possible for an oxide ion to migrate from one $\mathrm{M}(1) \mathrm{O}_{\mathrm{X}}$ unit to the other. The change in the oxygen fractional occupancies with temperature further supports the hypothesis that the oxide ion migration occurs via the partially occupied $\mathrm{O}(2)$ and $\mathrm{O}(3)$ sites $^{10}$.

Selected bond lengths and angles for $\mathrm{Ba}_{3} \mathrm{MoNbO}_{8.5}$ at the various temperatures are displayed in Table S2. Information on how the $\mathrm{M}$ polyhedra respond to the oxygen/vacancy rearrangement can be obtained by following some key bond lengths and angles. Figure 6 (b) shows a superimposition of the coordination of the $\mathrm{M}(1)$ $\mathrm{O}(1)_{3} \mathrm{O}(3)$ tetrahedra and the $\mathrm{M}(1)-\mathrm{O}(1)_{3} \mathrm{O}(2)_{3}$ octahedra. $\mathrm{M}(1)-\mathrm{O}(1)_{3} \mathrm{O}(3)$ and $\mathrm{M}(1)-\mathrm{O}(1)_{3} \mathrm{O}(2)_{3}$ share the same $\mathrm{M}(1) \mathrm{O}(1)_{3}$ unit, which presents three equal $\mathrm{M}(1)-\mathrm{O}(1)$ bond lengths and three equal $\mathrm{O}(1)-\mathrm{M}(1)-\mathrm{O}(1)$ angles $(\alpha)$. $\mathrm{M}(1)-\mathrm{O}(1)_{3} \mathrm{O}(3)$ is then defined by the $\mathrm{M}(1)-\mathrm{O}(3)$ bond length and the $\mathrm{O}(1)-\mathrm{M}(1)-\mathrm{O}(3)$ angle $(\beta)$, obtained by the average of the three possible angles given by the $\mathrm{O}(3)$ split position. The $\mathrm{M}(1)-\mathrm{O}(1)_{3} \mathrm{O}(2)_{3}$ octahedron is defined by the $\mathrm{M}(1)-\mathrm{O}(1)$ bond length, $\alpha$, the $\mathrm{M}(1)-\mathrm{O}(2)$ bond lengths and the $\mathrm{O}(1)-\mathrm{M}(1)-\mathrm{O}(2)$ and $\mathrm{O}(2)-\mathrm{M}(1)-\mathrm{O}(2)$ angles ( $\gamma$ and $\delta$ respectively). The temperature dependencies of selected distances and angles defined above are displayed in Figure 6 (a). All of the bond lengths and angles 
exhibit little variation with temperature below $300{ }^{\circ} \mathrm{C}$ but evidence a sizeable change above $300{ }^{\circ} \mathrm{C}$. Above $300{ }^{\circ} \mathrm{C}$ there is an increase in $\alpha$ and decrease in $\gamma, \beta$ and $\delta$. The $\mathrm{M}(1)-\mathrm{O}(1)$ bond length contracts whilst both $\mathrm{M}(1)-\mathrm{O}(3)$ and $\mathrm{M}(1)-\mathrm{O}(2)$ expand (Table S2, Figure 5 (a) and (b)).
The thermal modifications of the $\mathrm{M}(1)$ polyhedron are reflected to the neighbouring $\mathrm{M}(2) \mathrm{O}(1)_{6}$ octahedron where the $\mathrm{M}(2)-\mathrm{O}(1)$ bond lengths and the $\mathrm{O}(1)-\mathrm{M}(2)$ $\mathrm{O}(1)$ angles both increase with the temperature resulting in a net expansion of the $\mathrm{M}(2) \mathrm{O}(1)_{6}$ octahedra.

(a)

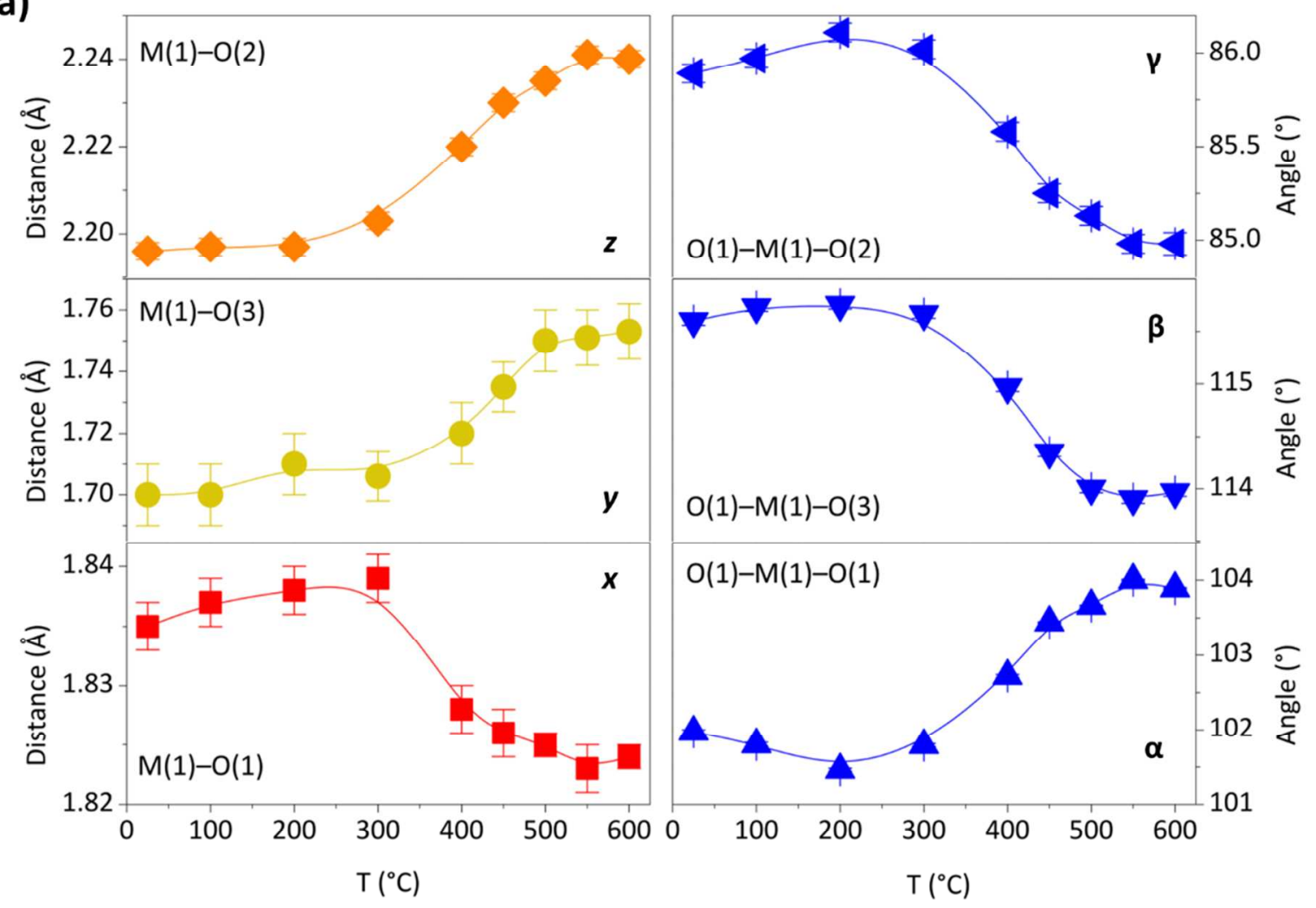

(b)

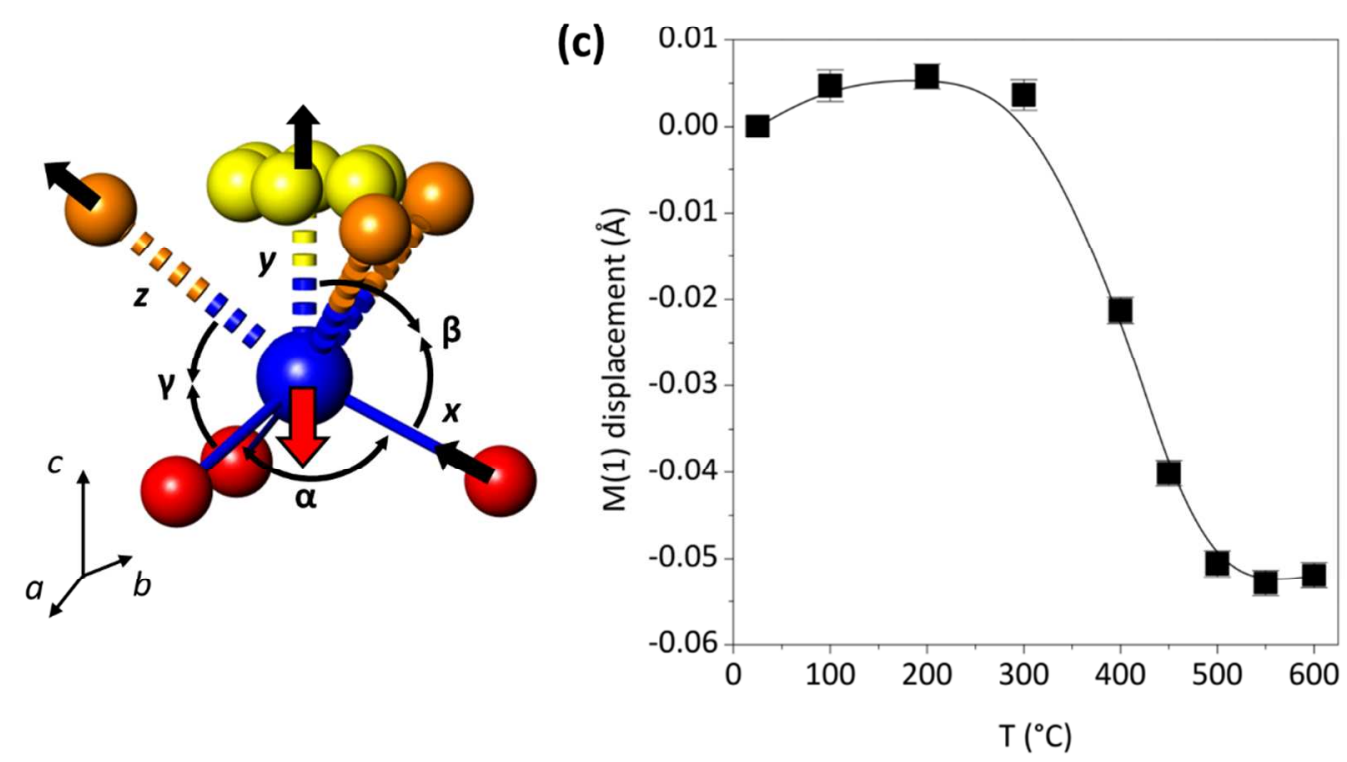

Figure 6. Thermal relaxation of the $M(1)$ polyhedra. Colours indicate: blue $M(1)$, cyan $M(2)$, red $O(1)$, orange $O(2)$ and yellow $\mathrm{O}(3)$ (a) Temperature dependency of selected bond distances and angles for the $\mathrm{M}(1)$ polyhedra. (b) Representation of the M-O lattice relaxation; black arrows show the modifications of the bond lengths and angles at $600{ }^{\circ} \mathrm{C}$ from the "equilibrium" values at $25^{\circ} \mathrm{C}$. The red arrow represents the average $M(1)$ displacement. (c) Variation of the M(1) displacement with the temperature. In (a) and (c) lines are guides for the eyes only; in the inset in (c) the red line is the linear fit to the data and the numbers are the calculated activation energies (in $\mathrm{eV}$ ). 
$\mathrm{Ba}_{3} \mathrm{MoNbO}_{8.5}$ presents an irregular thermal variation of the cell parameters, bond lengths and angles. These quantities exhibit nonlinear behaviour, with abrupt changes above $300{ }^{\circ} \mathrm{C}$. The trends in the variation of the cell parameters, bond lengths and angles with temperature mimic the thermal variation of the conductivity (Fig. 5) where the largest changes arise between $300{ }^{\circ} \mathrm{C}$ and 500 ${ }^{\circ} \mathrm{C}$. The $\mathrm{Ba}_{3} \mathrm{MoNbO}_{8.5}$ structure relaxes in response to the rearrangement of the oxygen/vacancy distribution. The $\mathrm{M}(1)$ polyhedra are already distorted at $25^{\circ} \mathrm{C}^{10}$ (Table S2), due to the effect of the second order Jahn-Teller distortion ${ }^{21}$. Examination of the variation of the $\mathrm{M}(1)-\mathrm{O}$ distances and angles with temperature indicates further displacement of the $\mathrm{M}(1)$ atom away from the $\mathrm{O}(2) / \mathrm{O}(3)$ sites, towards the $[\mathrm{O}(1)-\mathrm{O}(1)-\mathrm{O}(1)]$ face of the $\mathrm{M}(1)-\mathrm{O}(1)_{3}$ unit (Figure 5 (a) and (b)). The magnitude of the displacement $(D)$ can be obtained by calculation of the distance between $\mathrm{M}(1)$ and the $[\mathrm{O}(1)-\mathrm{O}(1)-\mathrm{O}(1)]$ face. This is given by $\mathrm{D}=-\mathrm{M}(1)-\mathrm{O}(1) \cos (\beta)$ and the displacement can be evaluated by the difference between the $\mathrm{M}(1)-[\mathrm{O}(1)$ $\mathrm{O}(1)-\mathrm{O}(1)]$ distance at temperature, $\mathrm{T}$, and the $\mathrm{M}(1)-[\mathrm{O}(1)$ $\mathrm{O}(1)-\mathrm{O}(1)$ ] distance at $25{ }^{\circ} \mathrm{C}$. The $\mathrm{M}(1)$ displacement is plotted against the temperature in Figure 6(c). The results clearly demonstrate that the variation of the oxygen/vacancy distribution above $300{ }^{\circ} \mathrm{C}$ strongly affects the relaxation of the $\mathrm{M}-\mathrm{O}$ framework. We note that the second order Jahn-Teller effect previously reported for $\mathrm{Ba}_{3} \mathrm{MoNbO}_{8.5}{ }^{10}$ may further enhance the distortion of the $\mathrm{MO}_{4} / \mathrm{MO}_{6}$ polyhedra, as distortions created by both electronic and structural effects are mutually supportive ${ }^{21}$. The $\mathrm{Ba}$ lattice relaxes in a similar way, with $\mathrm{Ba}(2)$ displacing away from $\left.\mathrm{O}(2) / \mathrm{O}_{3}\right)$ and consequent relaxation of the $\mathrm{Ba}(1)-\mathrm{O}$ framework (Figure $\mathrm{S}_{3}$ ).

Displacement of the metal atoms of the cationic lattice away from the mobile oxide ions has been reported in several different oxide ion conductors. In doped $\mathrm{LaGaO}_{3}$ perovskites, La and B-site cations shift away from the mobile oxygen atom ${ }^{22}$. Similarly, the $\mathrm{Si}$ atoms in the $\mathrm{La}_{9.33} \mathrm{Si}_{6} \mathrm{O}_{26}$ apatite move away from the channels in which migration of the interstitial oxygen atoms occurs ${ }^{23}$. In $\mathrm{Ba}_{3} \mathrm{MoNbO}_{8.5}$, the average $\mathrm{M}(1)$ displacement is an effect of the rearrangement of the oxygen/vacancy distribution at the $\mathrm{O}(2)$ and $\left.\mathrm{O}_{3}\right)$ sites but can also be correlated to the energetics of the ionic conduction as displacement of $d$-metal cations from oxygen vacancies in the lattice is thought to lower the motional enthalpy required for the mobility of the oxide ions ${ }^{24}$. The average structural relaxation, obtained from the neutron diffraction data, is therefore most likely a consequence of both the structural rearrangement and the dynamic and local structural reorganisation induced by the oxygen hopping.

The oxide ionic conductivity is thought to arise in the $\mathrm{Ba}(1) \mathrm{O}(2,3)_{2.5}$ layer. Oxygen mobility at the partially occupied $\mathrm{O}(2)$ and $\mathrm{O}(3)$ sites is evidenced by the change in the fractional occupancies with temperature. In addition the short distance between the $9 e$ and $36 i$ positions $(<2.2 \AA)$ excludes simultaneous occupancy of adjacent $\mathrm{O}(2)$ and $\mathrm{O}(3)$ sites. This leads to a random distribution of vacancies on the $\mathrm{Ba}(1) \mathrm{O}(2,3)_{2.5}$ layer, which are available for the ionic migration. The partially occupied $\mathrm{O}(2)$ and $\mathrm{O}(3)$ sites on the $\mathrm{Ba}(1) \mathrm{O}(2,3)_{2.5}$ layers are distributed in a zigzag fashion inside channels created by the rigid $\mathrm{Ba}(1), \mathrm{Ba}(2)$ and $\mathrm{O}_{1}$ ) framework (Figure $\mathrm{S}_{4}$ ). These channels propagate in the [10o], [o10] and [110] directions and might provide possible conduction pathways. It is most likely that the movement of oxide ions is via octahedral and tetrahedral interchange and suggests a cooperative motion such as an interstitialcy mechanism. ${ }^{10}$. This process is assisted by the ability of the system to locally and dynamically reorganise its oxygen/vacancy distribution. Above $300{ }^{\circ} \mathrm{C}$ it is proposed that the increase in the number of tetrahedra, coupled with the displacement of $\mathrm{M}(1)$ and $\mathrm{Ba}(2)$ away from $\mathrm{O}(2)$ and $\mathrm{O}_{3}$ ) enhances the electrical properties, so that a conductivity comparable to other leading solid oxide ion conductors is observed.

\section{CONCLUSIONS}

In summary this variable temperature neutron diffraction study demonstrates an unusual structural rearrangement in $\mathrm{Ba}_{3} \mathrm{MoNbO}_{8.5}$ above $300{ }^{\circ} \mathrm{C}$ so that the ratio of tetrahedra to octahedra increases and, consequently the oxygen/vacancy distribution changes as the temperature increases. We propose that the conductivity is enhanced by the increase in the proportion of $\mathrm{MO}_{4}$ tetrahedra between $300{ }^{\circ} \mathrm{C}$ and that substitution of $\mathrm{Nb}^{5+}$ with an aliovalent cation with preferential tetrahedral coordination may be a way to further optimise the conductivity at low temperature in $\mathrm{Ba}_{3} \mathrm{MoNbO}_{8.5}$. The change in vacancy distribution combined with the oxide ion migration results in displacement of the $\mathrm{M}(1)$ and $\mathrm{Ba}(2)$ sites away from the mobile oxygen, lowering the motional enthalpy required for the mobility of the oxide ions and enhancing the conductivity.

\section{ASSOCIATED CONTENT}

Supporting Information is available free of charge via the Internet at http://pubs.acs.org. The supporting information includes tables and figures of refined atomic positions and bond lengths and angles from Rietveld refinement of neutron diffraction data, figures of the Rietveld refinement fits to the neutron diffraction data at all temperatures and an alternative view of the $\mathrm{Ba}_{3} \mathrm{MoNbO}_{8.5}$ structure showing the rigid $\mathrm{Ba}-$ $\mathrm{O}(1)$ and the flexible $\mathrm{M}(1,2)-\mathrm{O}(2,3)$ frameworks.

\section{AUTHOR INFORMATION}

\section{Corresponding Author}

* a.c.mclaughlin@abdn.ac.uk

Tel: 00441224272924 Fax: 00441224272921

\section{Author Contributions}

The manuscript was written through contributions of all authors.

\section{ACKNOWLEDGMENT}

This research was supported by the Northern Research Partnership and the University of Aberdeen. We also acknowledge STFC-GB for provision of beamtime at the ILL.

\section{REFERENCES}


1. Kuang, X.; Payne, J. L.; Johnson, M. R.; Radosavljevic, I. E. Remarkably high oxide ion conductivity at low temperature in an ordered fluorite-type superstructure. Angew. Chemie - Int. Ed. 2012, 51, 690-694.

2. Kendrick, E.; Islam, M. S.; Slater, P. R. Developing apatites for solid oxide fuel cells: insight into structural, transport and doping properties. J. Mater. Chem. 2007, 10, 3104-3111.

3. Lacorre, P.; Goutenoire, F.; Bohnke, O.; Retoux, R.; Laligant, Y. Designing fast oxide-ion conductors based on $\mathrm{La}_{2} \mathrm{Mo2}_{2} \mathrm{O}$. Nature 2000, 404, 856-858.

4. Abraham, F.; Debreuille-Gresse, M. F.; Mairesse, G; Nowogrocki, G. Phase transition and ionic conductivity in $\mathrm{Bi}_{4} \mathrm{~V}_{2} \mathrm{O} 11$ an oxide with layered structure. Solid State Ionics 1988, 30, 529-532.

5. Kuang, X.; Green, M. A.; Niu, H.; Zajdel, P.; Dickinson, C.; Claridge, J. B.; Jantsky, L.; Rosseinsky, M. J. Interstitial oxide ion conductivity in the layered tetrahedral network melilite structure.et al. Nat. Mater. 2008, 7, 498-504.

6. Wachsman, E. D.; Lee, K. T. Lowering the temperature of solid oxide fuel cells. Science 2011, 334, 935-9.

7. Ishihara, T.; Matsuda, H.; Takita, Y. Doped LaGaO3 perovskite type oxide as a new oxide ionic conductor. J. Am. Chem. Soc. 1994, 116, 3801-3803.

8. Li, M.; Pietrowski, M. J.; De Souza, R. A.; Zhang, H.; Reaney, I. M.; Cook, S. N.; Kilner, J. A.; Sinclair, D. C. A family of oxide ion conductors based on the ferroelectric perovskite Nao.5Bio.5TiO3. Nat. Mater. 2014, 13, 31-5.

9. Fujii, K.; Esaki, Y.; Omoto, K.; Yashima, M.; Hoshikawa, A.; Ishigaki, T.; Hester, J. R. New perovskite related structure family of oxide ion conducting materials $\mathrm{NdBaInO}_{4}$. Chem. Mater. 2014, 26, 2488-2491.

10. Fop, S.; Skakle, J. M. S.; Mclaughlin, A. C.; Connor , P.; Irvine, J. T. S.; Smith, R. I.; Wildman, E. J. J. Am. Chem. Soc. Oxide ion conductivity in the hexagonal perovskite derivative $\mathrm{Ba}_{3} \mathrm{MoNbO}_{8.5}$. 2016, 138, 16764-16769.

11. Kuang, X.; Allix, M.; Ibberson, R. M.; Claridge, J. B.; Niu, H.; Rosseinsky, M. J.; Chem. Mater. Oxygen vacancy ordering phenomena in the mixed-conducting hexagonal perovskite $\mathrm{Ba}_{7} \mathrm{Y}_{2} \mathrm{Mn}_{3} \mathrm{Ti}_{2} \mathrm{O} 2 \mathrm{O} .2007$, 19, 2884-2893;

12. Ling, C. D.; Avdeev, M.; Kutteh, R.; Kharton, V. V.; Yaremchenko, A. A.; Fialkova, S.; Sharma, N.; Macquart, R. B.; Hoelzel, M.; Gutmann, M. Structures, phase transitions, hydration, and ionic conductivity of $\mathrm{Ba}_{4} \mathrm{Nb}_{2} \mathrm{O} 9$. Chem. Mater. 2009, 21, 38533864.

13. Larson, A. C.; Von Dreele, R. B. General structure analysis system (GSAS), Los Alamos National Laboratory Report LAUR 86-748. 1994.

14. B. H. Toby, EXPGUI, a graphical user interface for GSAS. J. Appl. Cryst., 2001, 34 (2001), 210.

15. Evans, I. R.; Howard, J. A. K.; Evans, J. S. O. The crystal structure of $\alpha-\mathrm{La}_{2} \mathrm{Mo}_{2} \mathrm{O}_{9}$ and the structural origin of the oxide ion migration pathway. Chem. Mater., 2005, 17, 4074-4077.

16. Mairesse, G.; Roussel, P.; Vannier, R. N.; Anne, M.; Pirovano, C.; Nowogrocki, G. Crystal structure determination of $\alpha, \beta$, and $\gamma$ - $\mathrm{Bi}_{4} \mathrm{~V}_{2} \mathrm{O}_{11}$ polymorphs. Part I: $\gamma$ and $\beta-\mathrm{Bi}_{4} \mathrm{~V}_{2} \mathrm{O} 11$, Solid State Sci., 2003, 5, 851-859.

17. Kajitani, M.; Matsuda, M.; Hoshikawa, A.; Harjo, S.; Kamiyama, T.; Ishigaki, T.; Izumi, F.; Miyake, M. In situ neutron diffraction study of fast oxide ion conductor $\mathrm{LaGaO}_{3}$-based perovskite compounds. Chem. Mater., 2005, 17, 4235-4243.

18. Stølen, S.; Bakken, E.; Mohn, C. E. Oxygen-deficient perovskites: linking structure, energetics and ion transport. Phys. Chem. Chem. Phys. 2006, 8, 429-447.

19. Goutenoire, F.; Isnard, O. ; Retoux, R.; Lacorre, P. Crystal structure of $\mathrm{La}_{2} \mathrm{Mo}_{2} \mathrm{O} 9$, a new fast oxide-ion conductor. Chem. Mater., 2000, 12, 2575-2580. 
2o. Abrahams, I.; Krok, F. Defect chemistry in the BIMEVOXes. J. Mater. Chem., 2002, 12, 3351-3362.

21. Kunz, M.; Brown, D. I. Out-of-center distortions around octahedrally coordinated do transition metals, J. Solid State Chem. $1995,115,395-406$.

22. Islam, M. S. Ionic transport in $\mathrm{ABO}_{3}$ perovskite oxides: a computer modelling tour. J. Mater. Chem., 2000, 10, 1027-1038.
23. Islam, M. S.; Tolchard, J. R.; Slater, P. R. An apatite for fast oxide ion conduction, Chem. Commun., 2003, 13, 1486-1487.

24. Goodenough, J. B.; Manthiram, A.; Paranthamam, M.; Zhen, Y. S. Oxide ion electrolytes. Mat. Sci. Eng. B-Solid, 1992, B12, $357 \cdot-364$
10

11

12

13

14

15

16

17

18

19

20

21

22

23

24

25

26

27

28

29

30

31

32

33

34

35

36

37

38

39

40

41

42

43

44

45

46

47

48

49

50

51

52

53

54

55

56

57

58

59

60 


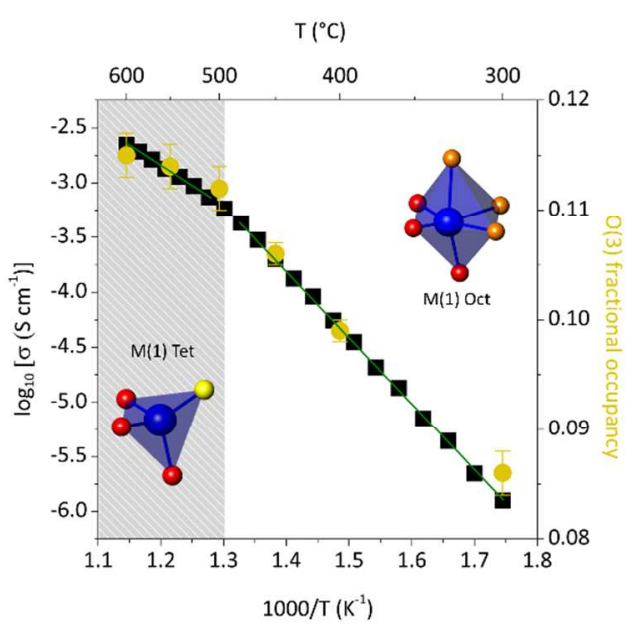

